\title{
Evaluation of complications and neurological deficits with three-column spine reconstructions for complex spinal deformity: a retrospective Scoli-RISK-1 study
}

\author{
Michael P. Kelly, M.D., ${ }^{1}$ Lawrence G. Lenke, M.D., ${ }^{1}$ Christopher I. Shaffrey, M.D., ${ }^{2}$ \\ Christopher P. Ames, M.D., ${ }^{3}$ Leah Y. Carreon, M.D., M.Sc., ${ }^{4}$ Virginie Lafage, Ph.D., 5 \\ Justin S. Smith, M.D., Ph.D., ${ }^{2}$ And Adam L. Shimer, M.D. ${ }^{6}$ \\ ${ }^{1}$ Department of Orthopaedic Surgery, Washington University School of Medicine, St. Louis, Missouri; \\ Departments of ${ }^{2}$ Neurological Surgery and ${ }^{6}$ Orthopedic Surgery, University of Virginia School of Medicine, \\ Charlottesville, Virginia; ${ }^{3}$ Department of Neurological Surgery, University of California, San Francisco, \\ California; ${ }^{4}$ Norton Leatherman Spine Center, Louisville, Kentucky; and ${ }^{5}$ Department of Orthopaedic \\ Surgery, New York University Medical Center, New York, New York
}

\begin{abstract}
Object. The goal in this study was to evaluate the risk factors for complications, including new neurological deficits, in the largest cohort of patients with adult spinal deformity to date.

Methods. The Scoli-RISK-1 inclusion criteria were used to identify eligible patients from 5 centers who were treated between June 1, 2009, and June 1, 2011. Records were reviewed for patient demographic information, surgical data, and reports of perioperative complications. Neurological deficits were recorded as preexisting or as new deficits. Patients who underwent 3-column osteotomies (3COs) were compared with those who did not (posterior spinal fusion [PSF]). Between-group comparisons were performed using independent samples t-tests and chi-square analyses.

Results. Two hundred seven patients were identified -75 who underwent PSF and 132 treated with 3CO. In the latter group, patients were older (58.9 vs 49.4 years, $\mathrm{p}<0.001)$, had a higher body mass index $(29.0$ vs 25.8 , p $=0.029)$, smaller preoperative coronal Cobb measurements $\left(33.8^{\circ}\right.$ vs $\left.56.4^{\circ}, \mathrm{p}<0.001\right)$, more preoperative sagittal malalignment $(11.7 \mathrm{~cm}$ vs $5.4 \mathrm{~cm}, \mathrm{p}<0.001)$, and similar sagittal Cobb measurements $\left(45.8^{\circ}\right.$ vs $\left.57.7^{\circ}, \mathrm{p}=0.113\right)$. Operating times were similar (393 vs 423 minutes, $\mathrm{p}=0.130$ ), although patients in the 3CO group sustained higher estimated blood loss (2120 vs $1700 \mathrm{ml}, \mathrm{p}=0.066)$. Rates of new neurological deficits were similar (PSF: $6.7 \%$ vs 3CO: $9.9 \%, p=0.389$ ), and rates of any perioperative medical complication were similar (PSF: $46.7 \%$ vs $3 \mathrm{CO}$ : $50.8 \%, \mathrm{p}=0.571)$. Patients who underwent vertebral column resection $(\mathrm{VCR})$ were more likely to sustain medical complications than those treated with pedicle subtraction osteotomy $(73.7 \%$ vs $46.9 \%, p=0.031)$, although new neurological deficits were similar $(15.8 \%$ vs $8.8 \%, \mathrm{p}=0.348)$. Regression analysis did not reveal significant predictors of neurological injury or complication from collected data.

Conclusions. Despite higher estimated blood loss, rates of all complications (49.3\%) and new neurological deficits $(8.7 \%)$ did not vary for patients who underwent complex reconstruction, whether or not a 3CO was performed. Patients who underwent VCR sustained more medical complications without an increase in new neurological deficits. Prospective studies of patient factors, provider factors, and refined surgical data are needed to define and optimize risk factors for complication and neurological deficits.

(http://thejns.org/doi/abs/10.3171/2014.2.FOCUS1419)
\end{abstract}

\section{KeY Words • complications • adult spinal deformity • osteotomy}

A DULT spinal deformity is associated with relatively high rates of perioperative complications, with a concordant increased risk of a new neurological deficit. . $7,10-12,15$ The combination of an aging population and the increasing number of spine fusion procedures results in an increasing number of patients with adult spinal deformities (ASDs), as well as an increasingly complex

\footnotetext{
Abbreviations used in this paper: ASD = adult spinal deformity; $\mathrm{BMI}=$ body mass index $; \mathrm{EBL}=$ estimated blood loss; $\mathrm{PCO}=$ posterior column osteotomy; $\mathrm{PSF}=$ posterior spinal fusion; $\mathrm{PSO}=$ pedicle subtraction osteotomy; $\mathrm{VCR}=$ vertebral column resection; $3 \mathrm{CO}=$ 3 -column osteotomy.
}

revision burden. ${ }^{13,14}$ With the rising revision burden, the diagnosis of fixed sagittal malalignment is increasingly common..$^{20}$ Numerous centers have reported their individual experiences, although few multicenter analyses of these patients with complex ASD exist.

Sagittal alignment is a primary driver of outcomes in ASD surgery. ${ }^{4,16}$ Although it is not the only factor, spinopelvic anatomy is one of the determinants of overall sagittal alignment. ${ }^{22}$ Multiple techniques have been proposed to restore lumbar lordosis in cases of fixed sagittal malalignment, including posterior column osteotomies (PCOs), pedicle subtraction osteotomies ([PSOs]-a 3-column osteotomy [3CO]), and combined anterior/ 
posterior procedures. ${ }^{2,3,5,8,9,21,24}$ A number of reports have shown higher rates of complications with the more invasive osteotomies (for example, 3CO) ${ }^{6,7,10}$ As techniques and experience evolve, however, the risk of complications, including neurological deficit, may be declining.

The Scoli-RISK-1 trial is a prospective observational cohort of patients undergoing surgery for major ASDs. A retrospective cohort study was performed using Scoli-RISK-1 inclusion criteria. In this study we sought to investigate the rates of complications occurring in major reconstructions performed at 5 centers participating in the Scoli-RISK-1 study. Specifically, we sought to examine whether $3 \mathrm{CO}$ is a risk factor for complication. As techniques have evolved, surgical complications may be minimized due to shorter operating times and better management of potential perioperative risk factors, including blood loss.

\section{Methods}

\section{Patient Selection}

Five centers participating in the Scoli-RISK-1 prospective cohort study were selected to identify patients treated between June 1, 2009, and June 1, 2011. The inclusion criteria are identical to those used to enroll patients in Scoli-RISK-1 and are found in Table 1. All patients were 18-80 years of age at the time of surgery and had major spinal deformities. Patients were excluded if they had a history of recent substance dependency, psychosocial disturbance, active malignancy, active bacterial infection (systemic or local), recent (within 3 months) trauma, prior paraplegia, or were pregnant or nursing.

\section{Data Collection}

Standardized data collection sheets were distributed to all participating centers. Preoperative data collected included age, sex, body mass index (BMI), primary diagnosis with Cobb and alignment measurements (C-7 coronal and sagittal), and any history of prior spine surgeries. Operative data collected included number of levels treated; whether osteotomies were performed and if yes, which type; estimated blood loss (EBL); and total operating time. Data regarding planned staged procedures were collected. Neurological and medical complications were gathered from reviews of medical records. Any mention of a postoperative motor or sensory deficit that was not recorded or consistent with a preoperative record was recorded as a new neurological deficit. Patients were divided into 2 groups: those undergoing a $3 \mathrm{CO}$ (PSO or vertebral column resection [VCR]), and those undergoing other reconstruction procedures (posterior spinal fusion [PSF]).

\section{Statistical Analysis}

The independent samples t-test was used to compare continuous data between groups. The chi-square test was used to compare rates of neurological deficit and medical complications between groups. Rates of these 2 complications were also examined for the PSO and VCR groups. Multivariate regression analysis with block entry was used to evaluate the relationship between known and reasonable predictors of a new perioperative neurological deficit and for any perioperative complication. Statistical significance was defined as $\mathrm{p}<0.05$. SPSS version 20 software (SPSS Inc.) was used for all analyses.

\section{Results}

Two hundred seven patients were identified and included in the analysis. Of these, 75 (53 women and 22 men) underwent a reconstruction without $3 \mathrm{CO}$. One hundred thirty-two patients (83 women and 46 men; information on gender was missing in 3 patients) underwent $3 \mathrm{CO}$ as part of the management of their deformity (PSO $=113$, VCR $=19$ ). Those patients undergoing $3 \mathrm{CO}$ were older and had a higher BMI. Patients who underwent $3 \mathrm{CO}$ had smaller maximum preoperative coronal Cobb measurements but similar preoperative maximum sagittal Cobb measurements. These patients had greater sagittal malalignment, according to the C-7 plumb line. Patients undergoing $3 \mathrm{CO}$ were more likely to have a preoperative motor deficit and were more likely to be undergoing a revision surgery. The distribution of American Society of Anesthesiologists scores was similar between groups (Table 2).

Total operating times were similar between groups, although the EBL was higher in the $3 \mathrm{CO}$ group (Table 3). Patients who underwent PSF had more coronal Cobb improvement, whereas those who underwent $3 \mathrm{CO}$ had greater sagittal alignment correction. Rates of new postoperative neurological deficits were similar (PSF: 5 [6.7\%] of 75, 3CO: 13 [9.9\%] of 132; p = 0.389). Rates of acute perioperative complications were similar also (PSF: 35 [46.7\%] of 75, 3CO: 67 [50.8\%] of 132; $\mathrm{p}=0.571)$. Major complications, as classified by Glassman et al., were similar between groups (PSF: 6 [8\%] of 75, 3CO: 19 [14\%] of $132 ; \mathrm{p}=0.12) .{ }^{17}$ Most patients suffering a perioperative complication sustained only one. Patients in the $3 \mathrm{CO}$

TABLE 1: Inclusion criteria for Scoli-RISK-1 


\section{Retrospective Scoli-RISK-1 study}

TABLE 2: Preoperative demographic data*

\begin{tabular}{|c|c|c|c|}
\hline \multirow[b]{2}{*}{ Variable } & \multicolumn{2}{|c|}{$3 \mathrm{CO}$} & \multirow[b]{2}{*}{$\mathrm{p}$ Value } \\
\hline & No & Yes & \\
\hline no. of patients & 75 & 132; 113 PSO, 19 VCR & \\
\hline age & $49.4 \pm 17 \mathrm{yrs}$ & $58.9 \pm 14$ yrs & $<0.001$ \\
\hline sex & & & 0.274 \\
\hline female & $53(70.7 \%)$ & $83(62.9 \%)$ & \\
\hline male & $22(29.3 \%)$ & $46(34.8 \%)$ & \\
\hline BMI & $25.8 \pm 9.5$ & $29 \pm 10.6$ & 0.029 \\
\hline preop max coronal Cobb angle deformity & $56.4^{\circ} \pm 34.4^{\circ}$ & $33.8^{\circ} \pm 30.7^{\circ}$ & $<0.001$ \\
\hline preop max sagittal Cobb angle deformity & $57.7^{\circ} \pm 38.4^{\circ}$ & $45.8^{\circ} \pm 46^{\circ}$ & 0.113 \\
\hline preop sagittal C-7 plumb alignment & $5.4 \pm 7.6 \mathrm{~cm}$ & $11.7 \pm 7.3 \mathrm{~cm}$ & $<0.001$ \\
\hline preop neurological deficit & & & 0.005 \\
\hline no & $58(77.3 \%)$ & $76(58 \%)$ & \\
\hline yes & $17(22.7 \%)$ & $55(42 \%)$ & \\
\hline revision procedure & & & $<0.001$ \\
\hline no & $30(43.5 \%)$ & $17(13.6 \%)$ & \\
\hline yes & $39(56.5 \%)$ & $108(86.4 \%)$ & \\
\hline ASA score & & & 0.096 \\
\hline 1 & $6(8.6 \%)$ & 7 (5.9\%) & \\
\hline 2 & $45(64.3 \%)$ & $57(47.9 \%)$ & \\
\hline 3 & $15(21.4 \%)$ & $49(41.2 \%)$ & \\
\hline 4 & $3(4.3 \%)$ & $5(4.2 \%)$ & \\
\hline
\end{tabular}

* Unless otherwise specified, the values are expressed as the mean \pm SD. Number discrepancies for sex in the 3 CO group (129 patients); preoperative neurological deficit in the $3 \mathrm{CO}$ group (131 patients); revision procedures in both groups (69 and 125 patients); and ASA score in both groups (69 and 118 patients) are due to missing data on the data collection sheets. ASA = American Society of Anesthesiologists; max = maximum.

TABLE 3: Perioperative data*

\begin{tabular}{|c|c|c|c|}
\hline \multirow[b]{2}{*}{ Variable } & \multicolumn{2}{|c|}{$3 \mathrm{CO}$} & \multirow[b]{2}{*}{$\mathrm{p}$ Value } \\
\hline & No & Yes & \\
\hline no. of patients & 75 & 132; 113 PSO, 19 VCR & \\
\hline op time & $422.9 \pm 140.9$ mins & $392.9 \pm 119.4$ mins & 0.130 \\
\hline mean EBL ( \pm SE) & $1700 \pm 182.1 \mathrm{ml}$ & $2120 \pm 135.3 \mathrm{ml}$ & 0.066 \\
\hline total levels fused & $11.5 \pm 4.6$ & $9.9 \pm 4.1$ & 0.014 \\
\hline postop max coronal Cobb angle deformity & $31.8^{\circ} \pm 27.2^{\circ}$ & $20.4^{\circ} \pm 19.3^{\circ}$ & $<0.001$ \\
\hline postop max sagittal Cobb angle deformity & $43.6^{\circ} \pm 30.3^{\circ}$ & $32.2^{\circ} \pm 36^{\circ}$ & 0.054 \\
\hline postop sagittal C-7 plumb alignment & $2.4 \pm 4.6 \mathrm{~cm}$ & $3.8 \pm 5.1 \mathrm{~cm}$ & 0.065 \\
\hline any medical complication & & & 0.571 \\
\hline no & $40(53.3 \%)$ & $65(49.2 \%)$ & \\
\hline yes & $35(46.7 \%)$ & $67(50.8 \%)$ & \\
\hline postop neurological deficit & & & 0.389 \\
\hline no & $70(93.3 \%)$ & $119(90.2 \%)$ & \\
\hline root level deficit & $2(2.7 \%)$ & $7(5.3 \%)$ & \\
\hline cauda equina syndrome & $0(0 \%)$ & $3(2.3 \%)$ & \\
\hline spinal cord deficit & $3(4 \%)$ & $3(2.3 \%)$ & \\
\hline
\end{tabular}

* Unless otherwise specified, the values are expressed as the mean \pm SD. 
group who underwent a VCR were more likely to sustain a perioperative complication, compared with those who underwent PSO (VCR: 14 [73.7\%] of 19, PSO: 53 [46.9\%] of 113; $p=0.031)$. Rates of new neurological deficits were similar between the PSO and VCR subgroups, however (PSO: 10 [8.8\%] of 113, VCR: 3 [15.8\%] of 19; $\mathrm{p}=0.348$ ).

Multivariate regression analyses did not reveal associations between the performance of a $3 \mathrm{CO}$ and a new postoperative deficit or medical complication when controlling for age, BMI, sex, EBL, and revision status.

\section{Discussion}

As the population ages, an increasing number of ASD surgeries will probably be performed. These surgeries often require multilevel, instrumented arthrodesis, and patients are at a higher risk for perioperative complications. ${ }^{13,14}$ With an improved awareness of the importance of sagittal alignment and lumbopelvic balance, more osteotomies, both $\mathrm{PCO}$ and $3 \mathrm{CO}$, are likely to be performed. Prior research has shown that patients undergoing 3COs may be at an increased risk for perioperative complications, including new neurological deficits. ${ }^{6,7}$ Whether the performance of the osteotomy or the nature of the deformity and other patient characteristics is the primary risk factor has not been appropriately examined. In this multicenter, observational cohort, we sought to investigate the relationship between perioperative complications (specifically neurological deficits) and 3COs in ASD surgery.

We identified 207 patients who had already been treated for their spinal deformity, who met the inclusion criteria for participation in the Scoli-RISK-1 trial. One hundred thirty-two patients underwent some type of $3 \mathrm{CO}$ as part of their reconstruction, with 113 patients treated with a PSO and 19 with a VCR. As expected, patients undergoing $3 \mathrm{CO}$ were more likely to have a severe preoperative sagittal plane malalignment. They also obtained greater sagittal plane realignment from the osteotomy. Also as expected, patients who underwent surgery with a $3 \mathrm{CO}$ had higher blood loss and longer operating times than patients treated with posterior reconstructions without osteotomy or with PCOs (for example, Smith-Petersen or Ponte) only. Despite higher blood loss, longer operating times, and the known increased technical difficulty associated with $3 \mathrm{CO}$, the rates of perioperative complication and neurological deficits were similar between the PSF and $3 \mathrm{CO}$ groups. Multivariate analysis did not indicate that any particular preoperative variable was associated with the development of a new neurological deficit or perioperative complication.

Prior work has indicated that a $3 \mathrm{CO}$ (PSO, VCR) may be a risk factor for perioperative complications. ${ }^{6,7,10-12}$ Increasing amounts of intraoperative blood loss and postoperative allogeneic blood transfusions have also been shown to increase the risk of a complication. The increased technical challenges associated with 3CO have been described as well, with the potential for an increase in complications concomitant with the technical complexities. ${ }^{1,6,7,18}$

Auerbach et al. ${ }^{1}$ reviewed the results of 3-column procedures at a single institution in an effort to differentiate the risk profiles of PSO and VCR. They reported an overall major complication rate of $35.2 \%$ (PSO 38\%, VCR $22 \%$ ), underscoring the high risk profile of these procedures. A preoperative sagittal malalignment of $40 \mathrm{~mm}$ or more, age greater than 60 years, and 3 or more medical comorbidities were associated with a postoperative major complication. Despite the serious nature of these complications, most patients were improved at a minimum of 2 years of follow-up, and no differences were observed between the improvements obtained with and without perioperative complications. Patients with permanent deficits were less satisfied with their procedure, although they did improve with surgery. Hassanzadeh et al. ${ }^{18}$ reported the results of PSO/VCR in patients older than 60 years of age and noted a similarly high complication rate (57\%: $18 \%$ major, 39\% minor). Again, despite these risks, significant improvements in outcomes scores were obtained, and the authors note that strict selection criteria should be used to determine eligible patients.

Revision surgeries, in particular, have been shown to have higher rates of complication in one series, whereas others have suggested that primary and revision surgeries have similar rates of early and late complications. ${ }^{10,19}$ Buchowski et al. ${ }^{7}$ noted an $11.1 \%$ rate of new neurological deficits in a series of 108 PSOs. The majority of these deficits were transient; the authors noted a permanent deficit rate of $2.8 \%$. These deficits were the result of inadequate decompression, subluxation, or buckling of the dura, suggesting that procedure factors and not patient factors play a role in the development of neurological deficits. Intraoperative neurological monitoring did not detect these deficits, limiting the ability of the surgeons to respond appropriately at the time of the initial surgery. Boachie-Adjei et al..$^{5}$ described their experience with PSO and reported a high complication rate $(58 \%)$. The majority of these complications had no effect on long-term patient outcomes, and only $12.5 \%$ of patients sustained neurological deficits. Two of the 3 neurological deficits were treated with a revision procedure, again suggesting that procedural and not patient factors remain the risk factor for developing a new neurological deficit.

In this study, which has the largest cohort of patients with $3 \mathrm{CO}$ investigated, we have found a rate of perioperative complications comparable to those previously presented in the literature, with an overall rate of $49.3 \%$. $^{1,5,6,18,24}$ Similarly, the rate of new neurological deficits was similar to published rates, with an overall rate of $8.7 \% .^{5,7}$ The rates of complication and neurological deficit were not statistically different between patients undergoing the more complex 3COs versus those treated with PCO-only procedures. We did not find that age, blood loss, or the performance of a $3 \mathrm{CO}$ predicted the occurrence of a complication, neurological or otherwise, with multivariate regression analysis.

The findings of these data analyses were surprising to us. The lack of significant findings with multivariate analysis may be due to the retrospective nature of the study. Our rates of perioperative complication and neurological deficit are probably lower than the true rates, due to the retrospective study design. Retrospective studies are subject to recall bias and are limited by what is 
available in the charts as these are reviewed. ${ }^{23}$ This was a multicenter effort and reporting probably varies between institutions. It may be that we have not collected the appropriate confounding variables and that other variables, such as surgeon experience, significantly correlate with complications and neurological deficits. The fact that Buchowski et al. ${ }^{7}$ found surgical technique to be at fault in the majority of their PSO-related neurological deficits supports this theory.

\section{Conclusions}

We have examined the rates of perioperative complications and neurological deficits in a cohort of patients with severe ASDs who met the criteria for enrollment in the Scoli-RISK-1 trial. We found an overall perioperative complication rate of $49.3 \%$, with a new neurological deficit rate of $8.7 \%$. These numbers agree well with prior published data. Interestingly, we did not observe an increase in complications or neurological deficits in patients undergoing 3COs, such as PSO or VCR. It may be that the complex deformity is the primary driver of the perioperative risks, rather than the procedure performed. Analysis of the data obtained from the prospective Scoli-RISK-1 trial will shed further light on this subject, to allow surgeons and patients to prepare adequately for the reconstructions and recoveries.

\section{Acknowledgments}

Dr. Kelly received support from the Washington University Institute of Clinical and Translational Sciences grant UL1TR000448 from the National Center for Advancing Translational Sciences (NCATS) of the NIH. The content is solely the responsibility of the authors and does not necessarily represent the official views of the NIH.

\section{Disclosure}

Dr. Shaffrey is a consultant for the following companies: Biomet, Globus, Medtronic, NuVasive, and Stryker. He also is a patent holder with and receives royalties from Biomet and Medtronic. Dr. Ames is a consultant for the following companies: DePuy, Medtronic, and Stryker. He owns stock in Visualase and Doctors Research Group, and he also owns Baxano Surgical. He is a patent holder with Fish \& Richardson, P.C., and receives royalties from Aesculap and Biomet Spine. Dr. Smith is a consultant for Biomet, DePuy, Medtronic, and Globus. He received clinical or research support from DePuy for this study and also for a non-study-related clinical or research effort that he oversaw. Dr. Lenke is a consultant for K2M, Medtronic, and DePuy Synthes Spine. He is a patent holder with Medtronic, and he receives royalties from Medtronic and Quality Medical Publishing. Dr. Carreon received support from Norton Healthcare, AO Spine, and the Orthopaedic Research and Education Fund (OREF) for a non-study-related clinical or research effort that she oversaw. She has the following research grants: from Norton Healthcare and AO Spine paid directly to Scoliosis Research Society for Scoli-RISK-1 Study 2010 and 2011; from OREF for the "Minimize Implants Maximize Outcomes" randomized controlled trial; and from Norton Healthcare for a study on "Risk of Osteoporotic Fracture after Epidural or Large Joint Steroid Injections." She has received monies for travel and accommodations from OREF, Department of Defense, and Association for Collaborative Spine Research for study planning meetings; from NIH for participation in review panels; and from the University of Louisville Institutional
Review Board (IRB) for annual required continuing education for IRB members. She has received the following honoraria: from NIH for participation in review panels; from Medtronic for participation in review panels and in their Global Evidence Advisory Board; and from Children's Tumor Foundation for participation in review panels. She is a member of the Editorial Advisory Board for Spine and Spine Journal and of the University of Louisville IRB. Medtronic provided funds directly to the database company; no funds were paid directly to Dr. Carreon or her institution (1/2002 to 9/2009). NuVasive provides funds directly to the database company. Dr. Shimer is a consultant for Medtronic.

Author contributions to the study and manuscript preparation include the following. Conception and design: Kelly, Lenke, Shaffrey, Ames, Smith, Shimer. Acquisition of data: Kelly, Carreon, Lafage, Shimer. Analysis and interpretation of data: Kelly, Shimer. Drafting the article: Kelly. Critically revising the article: Lenke, Shaffrey, Ames, Carreon, Lafage, Smith, Shimer. Reviewed submitted version of manuscript: all authors. Approved the final version of the manuscript on behalf of all authors: Kelly. Statistical analysis: Kelly, Shimer.

\section{References}

1. Auerbach JD, Lenke LG, Bridwell KH, Sehn JK, Milby AH, Bumpass D, et al: Major complications and comparison between 3-column osteotomy techniques in 105 consecutive spinal deformity procedures. Spine (Phila Pa 1976) 37:11981210,2012

2. Berven SH, Deviren V, Smith JA, Emami A, Hu SS, Bradford DS: Management of fixed sagittal plane deformity: results of the transpedicular wedge resection osteotomy. Spine (Phila Pa 1976) 26:2036-2043, 2001

3. Berven SH, Deviren V, Smith JA, Hu SH, Bradford DS: Management of fixed sagittal plane deformity: outcome of combined anterior and posterior surgery. Spine (Phila Pa 1976) 28:1710-1716, 2003

4. Blondel B, Schwab F, Ungar B, Smith J, Bridwell K, Glassman $\mathrm{S}$, et al: Impact of magnitude and percentage of global sagittal plane correction on health-related quality of life at 2-years follow-up. Neurosurgery 71:341-348, 2012

5. Boachie-Adjei O, Ferguson JA, Pigeon RG, Peskin MR: Transpedicular lumbar wedge resection osteotomy for fixed sagittal imbalance: surgical technique and early results. Spine (Phila Pa 1976) 31:485-492, 2006

6. Bridwell KH, Lewis SJ, Edwards C, Lenke LG, Iffrig TM, Berra A, et al: Complications and outcomes of pedicle subtraction osteotomies for fixed sagittal imbalance. Spine (Phila Pa 1976) 28:2093-2101, 2003

7. Buchowski JM, Bridwell KH, Lenke LG, Kuhns CA, Lehman RA Jr, Kim YJ, et al: Neurologic complications of lumbar pedicle subtraction osteotomy: a 10-year assessment. Spine (Phila Pa 1976) 32:2245-2252, 2007

8. Chang KW, Chen YY, Lin CC, Hsu HL, Pai KC: Closing wedge osteotomy versus opening wedge osteotomy in ankylosing spondylitis with thoracolumbar kyphotic deformity. Spine (Phila Pa 1976) 30:1584-1593, 2005

9. Chang KW, Cheng CW, Chen HC, Chang KI, Chen TC: Closing-opening wedge osteotomy for the treatment of sagittal imbalance. Spine (Phila Pa 1976) 33:1470-1477, 2008

10. Cho SK, Bridwell KH, Lenke LG, Yi JS, Pahys JM, Zebala LP, et al: Major complications in revision adult deformity surgery: risk factors and clinical outcomes with 2- to 7-year follow-up. Spine (Phila Pa 1976) 37:489-500, 2012

11. Daubs MD, Lenke LG, Cheh G, Stobbs G, Bridwell KH: Adult spinal deformity surgery: complications and outcomes in patients over age 60. Spine (Phila Pa 1976) 32:2238-2244, 2007

12. DeWald CJ, Stanley T: Instrumentation-related complications of multilevel fusions for adult spinal deformity patients over age 65: surgical considerations and treatment options in pa- 


\section{P. Kelly et al.}

tients with poor bone quality. Spine (Phila Pa 1976) 31 (19 Suppl):S144-S151, 2006

13. Deyo RA, Martin BI, Kreuter W, Jarvik JG, Angier H, Mirza SK: Revision surgery following operations for lumbar stenosis. J Bone Joint Surg Am 93:1979-1986, 2011

14. Deyo RA, Mirza SK, Martin BI: Error in trends, major medical complications, and charges associated with surgery for lumbar spinal stenosis in older adults. JAMA 306:1088, 2011 (Letter)

15. Emami A, Deviren V, Berven S, Smith JA, Hu SS, Bradford DS: Outcome and complications of long fusions to the sacrum in adult spine deformity: luque-galveston, combined iliac and sacral screws, and sacral fixation. Spine (Phila Pa 1976) 27: 776-786, 2002

16. Glassman SD, Bridwell K, Dimar JR, Horton W, Berven S, Schwab F: The impact of positive sagittal balance in adult spinal deformity. Spine (Phila Pa 1976) 30:2024-2029, 2005

17. Glassman SD, Hamill CL, Bridwell KH, Schwab FJ, Dimar JR, Lowe TG: The impact of perioperative complications on clinical outcome in adult deformity surgery. Spine (Phila Pa 1976) 32:2764-2770, 2007

18. Hassanzadeh H, Jain A, El Dafrawy MH, Ain MC, Mesfin A, Skolasky RL, et al: Three-column osteotomies in the treatment of spinal deformity in adult patients 60 years old and older: outcome and complications. Spine (Phila Pa 1976) 38: 726-731, 2013

19. Hassanzadeh H, Jain A, El Dafrawy MH, Mesfin A, Neubauer PR, Skolasky RL, et al: Clinical results and functional outcomes of primary and revision spinal deformity surgery in adults. J Bone Joint Surg Am 95:1413-1419, 2013

20. Kelly MP, Lenke LG, Bridwell KH, Agarwal R, Godzik J,
Koester L: Fate of the adult revision spinal deformity patient: a single institution experience. Spine (Phila Pa 1976) 38:E1196-E1200, 2013

21. Kim YJ, Bridwell KH, Lenke LG, Cheh G, Baldus C: Results of lumbar pedicle subtraction osteotomies for fixed sagittal imbalance: a minimum 5-year follow-up study. Spine (Phila Pa 1976) 32:2189-2197, 2007

22. Lafage V, Schwab F, Patel A, Hawkinson N, Farcy JP: Pelvic tilt and truncal inclination: two key radiographic parameters in the setting of adults with spinal deformity. Spine (Phila Pa 1976) 34:E599-E606, 2009

23. Mantel N, Haenszel W: Statistical aspects of the analysis of data from retrospective studies of disease. J Natl Cancer Inst 22:719-748, 1959

24. Yang BP, Ondra SL, Chen LA, Jung HS, Koski TR, Salehi SA: Clinical and radiographic outcomes of thoracic and lumbar pedicle subtraction osteotomy for fixed sagittal imbalance. J Neurosurg Spine 5:9-17, 2006

Manuscript submitted January 14, 2014.

Accepted February 28, 2014.

This paper was presented at the 48th Annual Meeting of the Scoliosis Research Society on September 19, 2013, in Lyon, France.

Please include this information when citing this paper: DOI: 10.3171/2014.2.FOCUS1419.

Address correspondence to: Michael P. Kelly, M.D., Department of Orthopaedic Surgery, IOH 5th Floor, Box 8233, 660 S. Euclid Ave., St. Louis, MO 63110. email: kellymi@wudosis.wustl.edu. 